\title{
Massive hemoptysis from pulmonary artery aneurysms
}

\author{
A KürQ̃t Bozkurt MD
}

AK Bozkurt. Massive hemoptysis from pulmonary artery aneurysms. Can Respir J 2002;9(1):33-34.

Aneurysms of the pulmonary arteries are rare. The author reports a case of a patient with bilateral pulmonary artery aneurysms, in whom the nature of the lesions was not known. Pulmonary artery aneurysms should be included in the differential diagnosis of lung masses.

Key Words: Aneurysm; Hemoptysis; Pulmonary artery

\section{Hémoptysie massive due à des anévrismes de l'artère pulmonaire}

Les anévrismes de l'artère pulmonaire sont rares. Voici le cas d'un patient présentant des anévrismes des deux artères pulmonaires, dont la nature des lésions est inconnue. Les anévrismes de l'artère pulmonaire devraient faire partie des diagnostics différentiels des masses décelées dans les poumons.
$\mathrm{P}^{\mathrm{u}}$ ulmonary artery aneurysms (PAAs) are rare. Previous articles have reported several associated diseases $(1,2)$, but idiopathic PAA has also been reported (3). A patient with bilateral PAAs was admitted because of a massive hemoptysis. He was investigated thoroughly for the etiology, but the workup was negative.

\section{CASE PRESENTATION}

A 40-year-old man was admitted to hospital because of massive hemoptysis. He reported expectoration of over $1 \mathrm{~L}$ of blood in the preceeding two days. His white blood cell count was 12,600 cells/ $\mu \mathrm{L}$, and his hemoglobin level was $12.4 \mathrm{~g} / \mathrm{dL}$; other laboratory studies were within normal limits. An admission chest radiograph showed large masses in both the left and right hilar regions (Figure 1). A computed tomography scan of the chest showed an aneurysm of the pulmonary trunk with dilation of both pulmonary arteries (pulmonary trunk, $5 \mathrm{~cm}$; right pulmonary artery, $6 \mathrm{~cm}$; left pulmonary artery, $5 \mathrm{~cm}$ ) (Figure 2).

The day after admission, the patient expectorated $600 \mathrm{~mL}$ of blood over $30 \mathrm{~min}$. An urgent pulmonary artery angiogram (reproduction quality was insufficient for publication) revealed a huge aneurysm extending toward both pulmonary arteries, which were filled with thrombus. The author had recently gained experience with the embolization of two leaking PAAs in patients with Behçet's disease. However, in the present case, the complete arterial tree from the main pulmonary artery to the lobar branches was aneurysmal, and the site of leaking could not be detected. High dose corticosteroid and azothiopirine were commenced (4). Interestingly, there was no further hemoptysis, although the size of the PAA did not change. The patient died suddenly one week later, without further hemoptysis. The family denied an autopsy.

Department of Thoracic and Cardiovascular Surgery, University of Istanbul, Cerrahpaşa Medical Faculty, Istanbul, Turkey Correspondence and reprints: AK Bozkurt, Ataköy 5. Kisim A7/40 34750 Istanbul, Turkey. Telephone +90-212-5608187, fax+90-212-5295600, e-mail akbozkurt@yahoo.com 


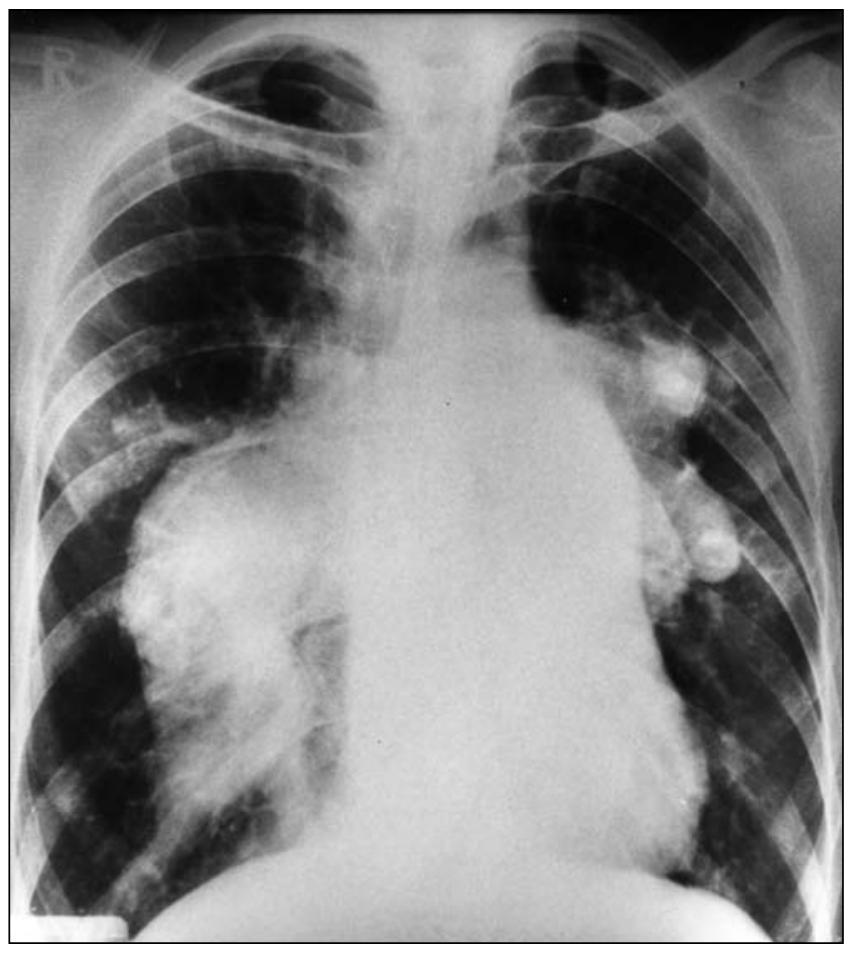

Figure 1) Chest radiograph showing huge masses in both the left and right hilum

\section{DISCUSSION}

PAA is a rare cause of massive hemoptysis in adults. An extensive review documented only eight cases among 109,571 autopsies performed over a 100-year period, and most were located in the main trunk of the pulmonary artery (1). The etiology and pathogenesis of PAAs are not well known. Approximately one-half are associated with congenital heart disease accompanied by pulmonary hypertension. Main PAAs may also be due to stenosis or absence of leaflets of the pulmonary valve. Other causes include syphilis, bacterial endocarditis, tuberculosis, cystic medial necrosis, vasculitis, hypertension and trauma $(1,2,5)$. Behçet's disease is well known to cause multiple aneurysms of the branch and main pulmonary arteries. PAAs occur in approximately $1 \%$ of patients, and Behçet's disease is reported to be the most common cause of PAAs (5).

Computed tomography scans and magnetic resonance imaging are the diagnostic modalities of choice for PAAs, because these aneurysms may not be demonstrated by conventional angiography if completely thrombosed (6). There is no definitive therapeutic approach for this lesion because of the paucity of information about its natural history and the long term outcome after medical or surgical intervention (7). The recommended initial treatment to control hemoptysis is embolization. Surgical management should be considered for large aneurysms of the pulmonary trunk regardless of the etiology and underlying disease to prevent possible rupture, if the patient has an acceptably low operative risk (7).

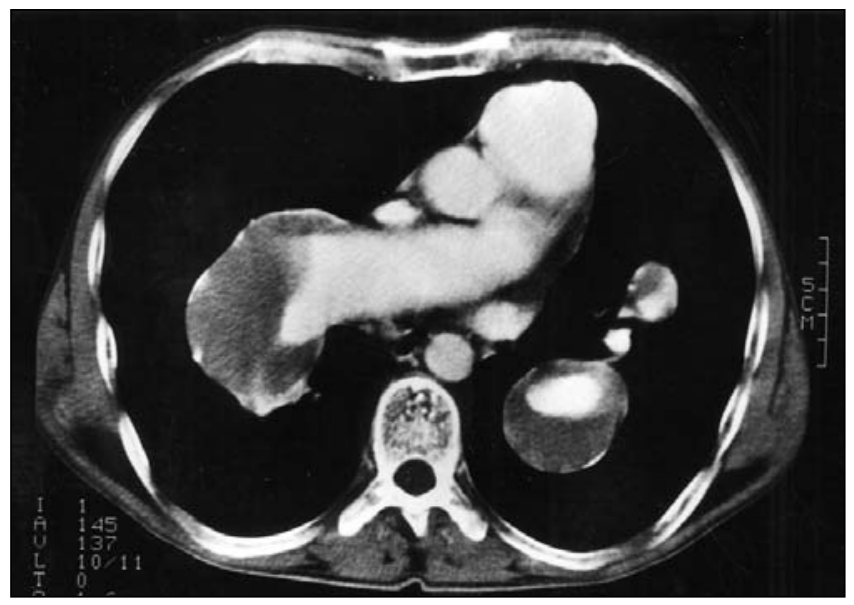

Figure 2) Computed tomography scan of the chest showing an aneurysm of the pulmonary trunk with dilation of bilateral pulmonary arteries

Possible causes of PAA were considered in the present patient, including structural heart defects, syphilis, bacterial endocarditis, tuberculosis, rare vasculitic syndromes such as the Hughes-Stovin syndrome, hereditary telangiectasia and giant cell arteritis, but none were detected. The diagnosis of Behçet's disease was excluded because of the absence of oral and genital ulceration, and because the patient's blood was negative for the human leukocyte B51 antigen. There was no surgical indication because of the bilateral and diffuse nature of the aneurysms. Bilateral lung transplantation would have been a possible alternative if the patient had survived longer. We did not attempt embolization, because the site of leakage was not seen, and blockage of the huge aneurysm was not possible.

The deficiency in this report is the absence of a postmortem examination. Unfortunately, the family denied an autopsy because of religious reasons. We have not encountered such a diffuse and bilateral aneurysm formation in our wide experience of Behçet's disease or in the literature, but there is a need for awareness of the possibility of PAA as a cause of massive hemoptysis.

\section{REFERENCES}

1. Deterling RA, Clagett OT. Aneurysm of the pulmonary artery: review of literature and report of a case. Am Heart J 1947;34:471-99.

2. Bartter T, Irwin RS, Nash G. Aneurysms of the pulmonary arteries review. Chest 1988;94:1065-75

3. Fang CC, Tsai CC. Idiopathic pulmonary artery aneurysm. J Formos Med Assoc 1996;95:873-6.

4. Stricker H, Malinverni R. Multiple, large aneurysms of pulmonary arteries in Behçet's disease. Clinical remission and radiologic resolution after corticosteroid therapy. Arch Intern Med 1989;149:925-7.

5. Tunaci A, Berkman YM, Gokmen E. Thoracic involvement in Behçet disease: Pathologic, clinical, and imaging features. AJR Am J Roentgenol 1995;164:51-6.

6. Numan F, Islak C, Berkmen T, et al. Behçet disease: Pulmonary arterial involvement in 15 cases. Radiology 1994;192:465-8.

7. Kuwaki K, Morishita K, Sato H, Urita R, Abe T. Surgical repair of the pulmonary trunk aneurysm. Eur J Cardiothorac Surg 2000;18:535-9. 


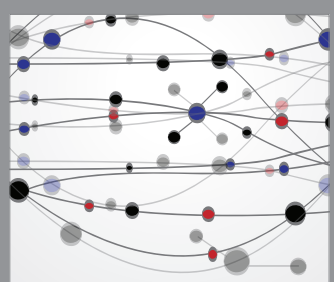

The Scientific World Journal
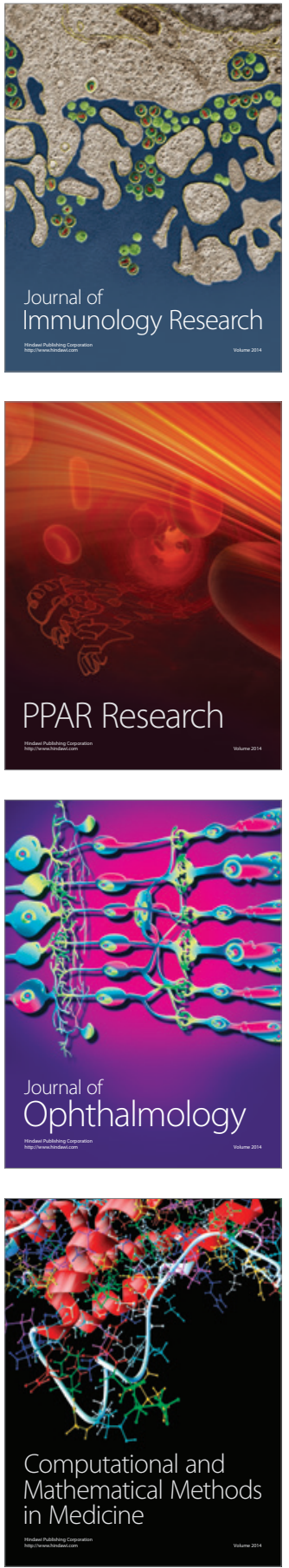

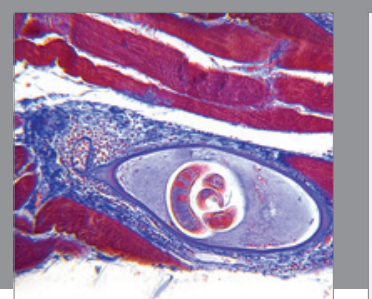

Gastroenterology Research and Practice

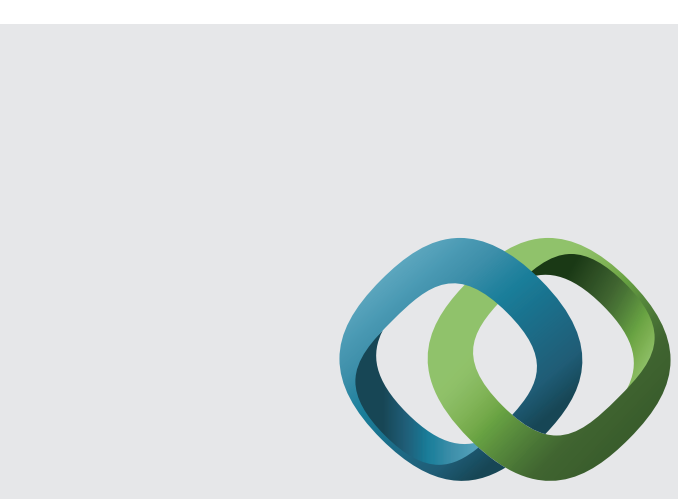

\section{Hindawi}

Submit your manuscripts at

http://www.hindawi.com
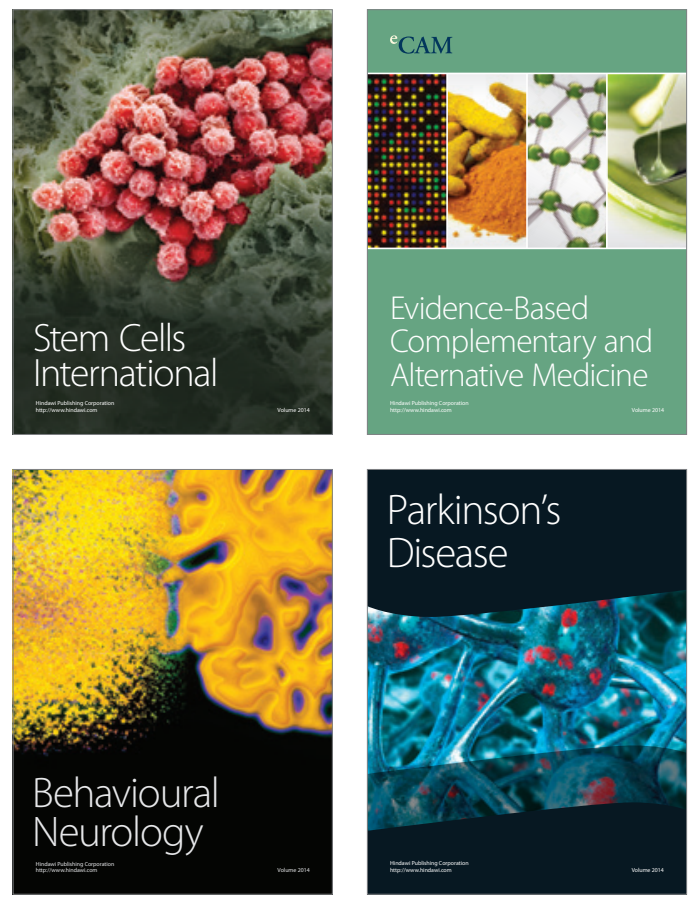
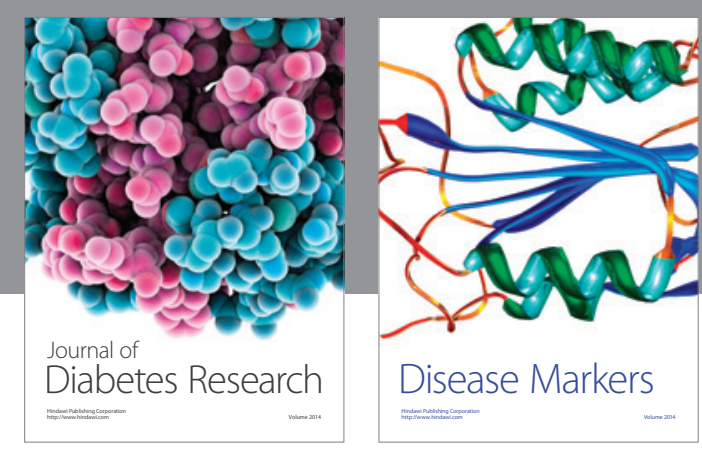

Disease Markers
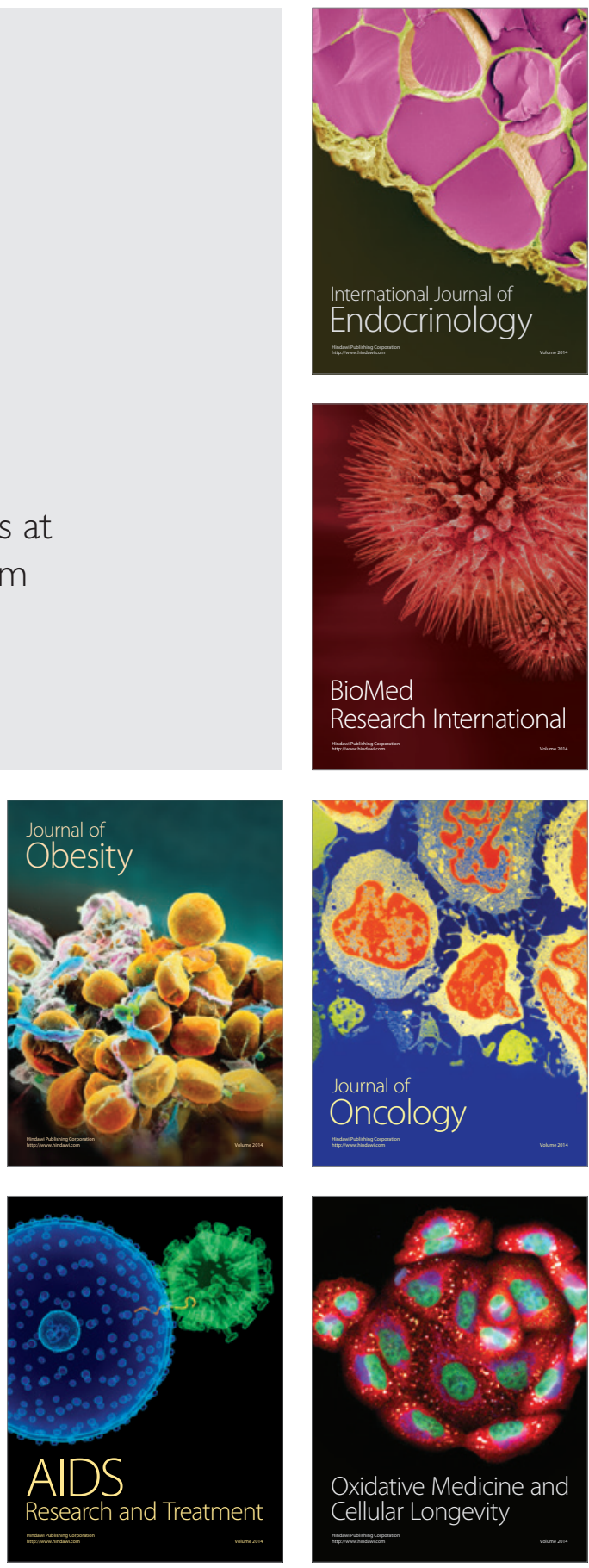